\title{
Influência da presença de óxidos no aquecimento micro-ondas de arenitos
}

Influenceofthepresence of oxidesonmicrowavesheating of sandstones

\author{
1 André Silveira andresilveirafelipe@gmail.com \\ 1 Irineu Petri
}

1 Universidade Federal de Lavras.

\section{RESUMO}

Na perfuração de poços que contêm petróleo, são utilizadas brocas que, ao penetrarem na matriz rochosa, geram fragmentos que são conhecidos como cascalho. 0 cascalho é transportado até a superfície pelo fluido de perfuração que possui baixa biodegrabilidade, fazendo com que seja necessária uma separação para que o cascalho possa ser descartado de forma adequada ao meio ambiente. A secagem via micro-ondas está sendo utilizada para a descontaminação desses cascalhos, pois apresenta alta eficiência de remoção comparada a equipamentos convencionais. $\mathrm{O}$ aquecimento micro-ondas é fortemente influenciado pela composição química da matriz rochosa. Sendo assim, nesta pesquisa, foram verificados a influência dos óxidos de ferro, alumínio, manganês e cálcio, que são óxidos comumente presentes no cascalho contaminado, no aquecimento micro-ondas de um arenito, com o objetivo de difundir a praticidade e eficiência dessa técnica de descontaminação. Os testes foram efetuados em um micro-ondas de bancada adaptado, a fim de se verificar como as variações de composição afetam a cinética de temperatura e taxa de aquecimento. Com base nos resultados obtidos, foi possível identificar que o óxido de ferro possui maior sensibilidade às micro-ondas comparado ao óxido de alumínio, devido ao fato de que as propriedades eletromagnéticas estão presentes no ferro, acarretando em maior taxa de aquecimento. 0 óxido de manganês foi o que apresentou maior taxa de aquecimento, porém foi observado uma anormalidade no aquecimento da amostra após certo tempo de exposição às micro-ondas. Por não absorver de forma adequada às micro-ondas, o óxido de cálcio foi o que apresentou menor taxa de aquecimento em comparação aos demais. Com os resultados obtidos, foi possível também desenvolver uma correlação para prever como cada tipo de óxido estudado comporta ao ser submetido ao aquecimento micro-ondas.

\section{Palavras-chave:}

Propriedades dielétricas. Ondas eletromagnéticas. Aquisição de dados.

\begin{abstract}
In the drilling of wells containing oil, drills are used that, when penetrating the rocky matrix, generate fragments, known as gravel. The gravel is transported to the surface by the drilling fluid, which has low biodegradability, making it necessary to separate it so that the gravel can be disposed of in an environmentally friendly manner. Microwave drying is being used to decontaminate these cuttings, as it has a high removal efficiency compared to conventional equipment. Microwave heating is strongly influenced by the chemical composition of the rock matrix. Therefore, in this work, the influence of the presence of iron, aluminum, manganese and calcium, which are oxides commonly present in contaminated gravel on the microwave heating of a sandstone was verified, in order to spread the practicality and efficiency of this decontamination technique. The tests were carried out in an adapted bench microwave, in order to verify how the variations in composition affect the temperature kinetics and heating rate. Based on the results obtained, it was possible to identify that iron oxide has greater sensitivity to microwaves compared to aluminum oxide, due to the fact of the electromagnetic properties present in iron, resulting in a higher heating rate. Manganese oxide was the one with the highest heating rate, however, an abnormality in the heating of the sample was observed after a certain time of exposure to microwaves. For not absorbing properly the microwave, calcium oxide showed the lowest rate of heating compared to the others. By the results obtained, it was also possible to develop a correlation to predict how each type of oxide studied behaves when subjected to microwave heating.
\end{abstract}

\section{Keywords:}

Dielectric properties. Electromagnetic waves. Data acquisition.

\section{Como você deve citar?}

SILVEIRA, André; PETRI, Irineu. Influência da presença de óxidos no aquecimento micro-ondas de arenitos. Cadernos UniFOA, Volta Redonda, n. 45, p. 23- 33, abril 2021. 


\section{INTRODUÇÃO}

Considerado uma das principais fontes de primárias de energia, o petróleo é composto por hidrocarbonetos oriundos da decomposição de matéria orgânica. Para a sua extração, é necessária a perfuração de uma matriz rochosa, com auxílio de uma broca. Os fragmentos gerados são conhecidos como cascalhos de perfuração e sua retirada é feita pelo fluido de perfuração, que entra pelo interior da broca e retorna à superfície por um espaço entre as paredes do poço e a coluna de perfuração.

Os fluidos de perfuração são misturas complexas de sólidos, líquidos e gases e possui especificações, como estabilização das paredes do poço, ser bombeável e estável quimicamente, apresentar baixa corrosão e abrasão na coluna de perfuração e possuir um custo compatível com a operação, além de ser responsável por manter a broca resfriada.

Porém, a aplicação do fluido de perfuração apresenta uma desvantagem com relação à sua baixa biodegrabilidade. Sendo assim, o descarte do cascalho deve atender aos requisitos ambientais descritos na legislação, em que os limites para o descarte são definidos pelo Instituto Brasileiro de Meio Ambiente e de Recursos Renováveis (IBAMA).

Atualmente, as exigências feitas pelos órgãos ambientais estão cada vez maiores. Sendo assim, o processo de descarte de resíduos da indústria petrolífera tem se tornado cada vez mais rigoroso, sendo necessária a procura por novas tecnologias para a descontaminação dos cascalhos contaminados pelo fluido de perfuração. A tecnologia de secagem por micro-ondas para descontaminação de cascalhos provenientes da perfuração de poços de petróleo é, relativamente, nova e tem grande potencial de crescimento.

\section{REVISÃO DA LITERATURA}

Segundo Pereira (2013) e Panisset (2014), um método bastante utilizado para o tratamento do cascalho contaminado é a utilização de uma centrífuga filtrante que seca o cascalho, reduzindo os teores de contaminantes a níveis permitidos pela legislação ambiental. Porém, a centrífuga filtrante opera com uma margem muita próxima ao teor dos contaminantes permitidos por lei e, a operação pode ser prejudicada devido ao mau funcionamento do equipamento. Os estudos citados mostram que a secagem via micro-ondas possui capacidade de reduzir os teores de contaminantes em cerca de $1 \%$, em massa, sendo então mais interessante a sua utilização, pois o aquecimento ocorre em nível molecular, aumentando a eficiência de remoção.

Javad (2012) afirma que as micro-ondas possuem potencial para aplicações no tratamento de minerais e na recuperação de processos de elementos metálicos como aquecimento, secagem, moagem, lixiviação, torrefação, fundição, redução carbotérmica de minerais com a presença de determinados óxidos e pré-tratamento de refratários e minérios. 0 estudo afırma também que a eficiência do aquecimento por micro-ondas é maior do que a eficiência realizada por um aquecimento convencional, fazendo com que o gasto de energia seja irrelevante. Portanto, para a recuperação de um produto de alto valor ou um tratamento de certa quantidade de algum material, a utilização do aquecimento via micro-ondas oferece uma vantagem de custo e eficiência sobre o processo convencional.

A secagem de cascalhos contaminados com fluido de perfuração foi realizada por Shang et al. (2005), os autores utilizaram um micro-ondas de escala laboratorial, reduzindo o teor de óleo contaminante do cascalho de perfuração em níveis abaixo a 1\%. Foi concluído que a potência aplicada e o tempo de aquecimento são fatores primordiais na secagem. 
Robinson et al. (2009) utilizaram um agitador mecânico para testes de secagem via micro-ondas com cascalho contaminado com fluido de perfuração. Os resultados mostraram que a eficiência de remoção do processo passou de $40 \%$ para $90 \%$. A agitação do material contaminado contribuiu para o aumento na remoção dos contaminantes devido à profundidade de penetração das micro-ondas.

Segundo Petri Júnior et al. (2017), a secagem via micro-ondas está sendo utilizada para a descontaminação dos cascalhos contaminados com o fluido de perfuração, pois apresenta alta eficiência de remoção comparada a equipamentos convencionais, devido ao fato de os teores de óxidos presentes na matriz rochosa influenciarem diretamente no aquecimento.

A utilização das micro-ondas é feita de maneira seletiva nos óxidos encontrados nos minérios devido aos diferentes valores das propriedades dielétricas dos óxidos. Além disso, para materiais com baixa absorção de micro-ondas, é possível aquecê-los, utilizando-se alguns óxidos que atuam como um veículo de aquecimento pelo fato de absorverem bem as micro-ondas.

De acordo com o descrito, o objetivo desta pesquisa foi estudar a influência de diferentes óxidos no aquecimento micro-ondas ( $2450 \mathrm{MHz}$ ) de arenitos, a fım de se determinar como as variações de composição afetam a cinética de temperatura, possibilitando a descoberta da taxa de aquecimento para cada óxido presente na matriz rochosa. Além disso, foi verificado a influência também da potência do micro-ondas na cinética de aquecimento em alguns óxidos e proposto uma correlação que descrevesse a influência de todos os parâmetros avaliados na taxa de aquecimento do arenito em função do óxido presente.

\section{MATERIAIS E MÉTODOS}

Para avaliar o aquecimento dos arenitos em função do teor de óxido, foi utilizado um forno micro-ondas de baixa potência (1), da marca Brastemp, modelo BMP40EGAAB, mostrado pela Figura 1. Para realização dos experimentos, utilizou-se areia normal brasileira - ANB média-grossa (arenito), misturada com determinados teores de óxidos de ferro III, óxido de alumínio, óxido de manganês e óxido de cálcio, todos eles reagentes P.A. As amostras de areia com óxidos foram alocadas em recipientes de cerâmica (2) e inseridas no centro da cavidade para seu aquecimento. Para monitoramento on-line da temperatura (5), foi utilizada uma aquisição de dados constituída por uma placa micro controladora Arduino UNO (4), acoplada a um termopar do tipo K (3). Para avaliar a influência da potência no aquecimento de arenitos com diferentes óxidos, foi utilizado também um forno micro-ondas de média potência, da marca Electrolux MEF41, acoplado ao mesmo sistema de aquisição.

Ao início dos experimentos, foram verificadas as potências reais de saída dos fornos micro-ondas, segundo a norma IEC 60705 (International Electrotechnical Commission), norma para mensurar a eficiência do micro-ondas e, segundo a Portaria no $174 / 2012$ do INMETRO (Instituto Nacional de Metrologia, Qualidade e Tecnologia), que se caracteriza por ser um regulamento técnico da qualidade para fornos micro-ondas. 
Figura 1 - Unidade experimental com forno de micro-ondas de baixa potência acoplado ao sistema de aquisição de dados.

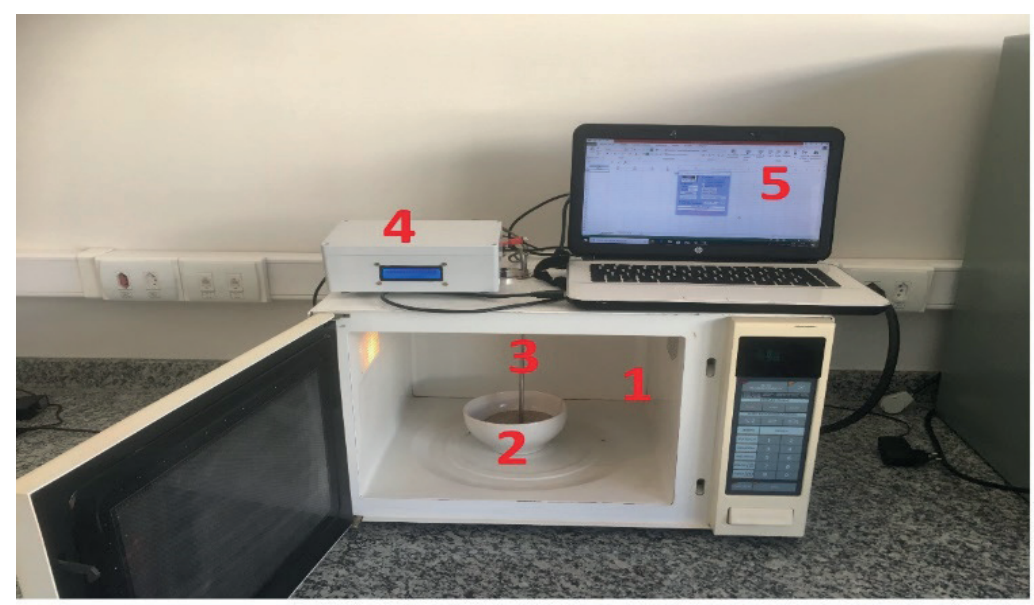

Fonte: Autoria própria

As potências de saída foram aferidas ao início dos experimentos. A Tabela 1 mostra os resultados de potência de saída dos fornos micro-ondas utilizados na pesquisa.

Tabela 1 - Resultados de potência de saída dos fornos micro-ondas.

\begin{tabular}{ccc}
\hline \multirow{2}{*}{ Forno micro-ondas } & \multicolumn{2}{c}{ Potência de Saída [W] } \\
\cline { 2 - 3 } & Média & Desvio Padrão \\
\hline Brastemp BMP40EGAAB & 467,97 & 10,97 \\
(baixa potência) & 672,25 & 37,57 \\
\hline $\begin{array}{c}\text { Electrolux MEF41 } \\
\text { (média potência) }\end{array}$ & & \\
\hline
\end{tabular}

Fonte: Autoria própria

A diferença entre os resultados experimentais e os resultados fornecidos pelos fabricantes dos dois fornos (900W) mostra que houve desgaste, com o passar do tempo, de seu principal componente, 0 magnetron, que possui a capacidade de produzir as ondas eletromagnéticas de pequeno comprimento, conhecidas como micro-ondas. Sendo assim, a aferição da potência do micro-ondas, antes de se realizar os experimentos, é de extrema importância para que se possa conduzir os experimentos de forma adequada e conseguir mensurar quanto a potência está defasada da daquela informada pelo fabricante.

Para realização dos experimentos, primeiramente, foram preparadas as amostras, nas quais os teores de óxidos na mistura com o arenito foram variados de 10 a 35\%, com uma massa total de 300 gramas de cada amostra. Entretanto, antes de se adicionar óxidos às amostras, foram realizados vários testes em branco, em que somente o arenito (teor referente a $0 \%$ ) foi aquecido no forno micro-ondas de baixa e média potência.

Após a preparação das amostras, uma por uma, elas eram inseridas no interior da cavidade e o termopar era alocado na amostra, sendo submetidas ao aquecimento pelo micro-ondas, por um tempo que dependia do comportamento do material. Esse tempo variava entre 3 e 6 minutos. Durante o teste, o leito absorvia as micro-ondas e as convertia em calor e, com isso, o termopar aferia a temperatura e a registrava 
em uma planilha, salvando-as no computador. Com a aquisição dos dados concluída, foi possível interpretar a cinética de temperatura em função do teor de óxido na amostra e suas respectivas taxas de aquecimento.

Os testes foram realizados em triplicata e os resultados apresentados se tratam de uma média aritmética dos valores.

\section{RESULTADOS E DISCUSSÃO}

A Figura 2 mostra a cinética de aquecimento do arenito misturado com óxido de ferro III com teores de $0,10,20,25$ e $35 \%$, quando aquecidos no forno de baixa potência ( $468 \mathrm{~W}$ ) e com teores de 0 e $25 \%$, quando aquecidos no forno de média potência ( $672 \mathrm{~W}$ ).

Pela Figura 2, quando comparado ao teste branco (0\%), é possível observar que a presença do óxido de ferro causa um grande aumento na inclinação das curvas de cinética à $468 \mathrm{~W}$, indicando que o mesmo é bastante reativo às micro-ondas. Quanto maior o teor de óxido, mais rápido ocorre o aquecimento do arenito. Foi possível alcançar temperaturas superiores a $300^{\circ} \mathrm{C}$ com apenas 6 minutos de aquecimento, classificando o óxido de ferro III como um bom absorvedor de micro-ondas, assim como previsto por Petri Júnior et al. (2017).

Figura 2 - Cinética de aquecimento areia com diferentes teores de óxido de ferro e potências.

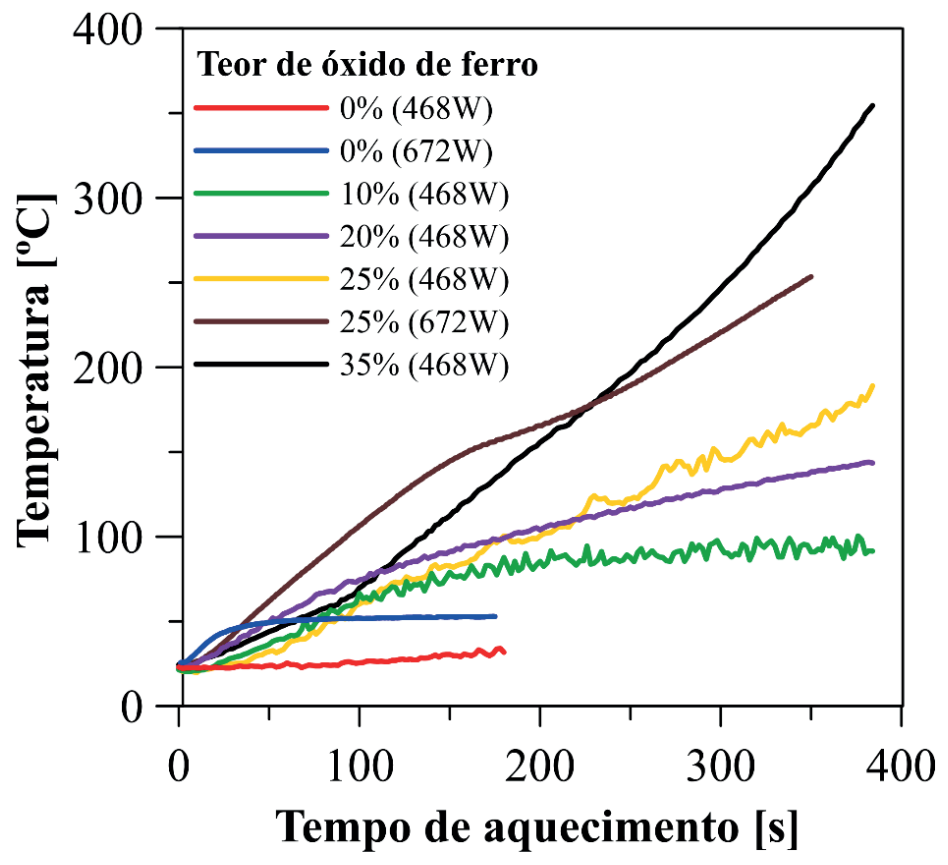

Fonte: Autoria própria

Aumentando-se a potência de 468W para $672 \mathrm{~W}$, em um mesmo teor, é possível alcançar maiores temperaturas, visto que há maior quantidade de energia sendo convertida em calor. Experimentalmente, aumentando-se a potência e utilizando-se o teor de $25 \%$ de óxido de ferro, foi possível verificar uma maior instabilidade no aquecimento, causando, por vezes, a sinterização do arenito na ponta do termopar. Para teores a partir de $25 \%$, as curvas apresentaram um comportamento exponencial, sugerindo que, a partir desse teor, o aquecimento do arenito pode se tornar instável. Isso indica que é necessário ter cautela no aquecimento de materiais com altas concentrações de óxido de ferro. 
A cinética de aquecimento do arenito com óxido de alumínio a teores de 10,20, 25 e 35\% aquecidos no forno de baixa potência ( $468 \mathrm{~W}$ ) e a teor de $20 \%$ aquecido no forno de média potência ( $672 \mathrm{~W}$ ) estão ilustrados na Figura 3.

As cinéticas de aquecimento do arenito com óxido de alumínio à baixa potência, apresentados na Figura 3, mostram que a presença do alumínio não influencia tanto na cinética de aquecimento quanto ao que foi observado pelo óxido de ferro. As inclinações das curvas pouco se diferenciam da inclinação do teste branco $(0 \%)$. Porém, ainda é possível constatar que a presença do óxido de alumínio causa um pequeno aumento na temperatura do arenito, classificando-o como um óxido com insatisfatória absorção de micro-ondas.

0 aumento do seu teor promove um aumento na inclinação da curva de aquecimento, principalmente para as temperaturas mais elevadas. Vale ressaltar que, assim como dito por Petri Júnior et al. (2017), as propriedades dielétricas do óxido de alumínio sofrem bastante influência com a temperatura. Logo, mesmo não sendo um absorvedor a baixas temperaturas, sugere passar a ser um bom absorvedor a altas temperaturas.

Figura 3 - Cinética de aquecimento areia com diferentes teores de óxido de alumínio e potências.

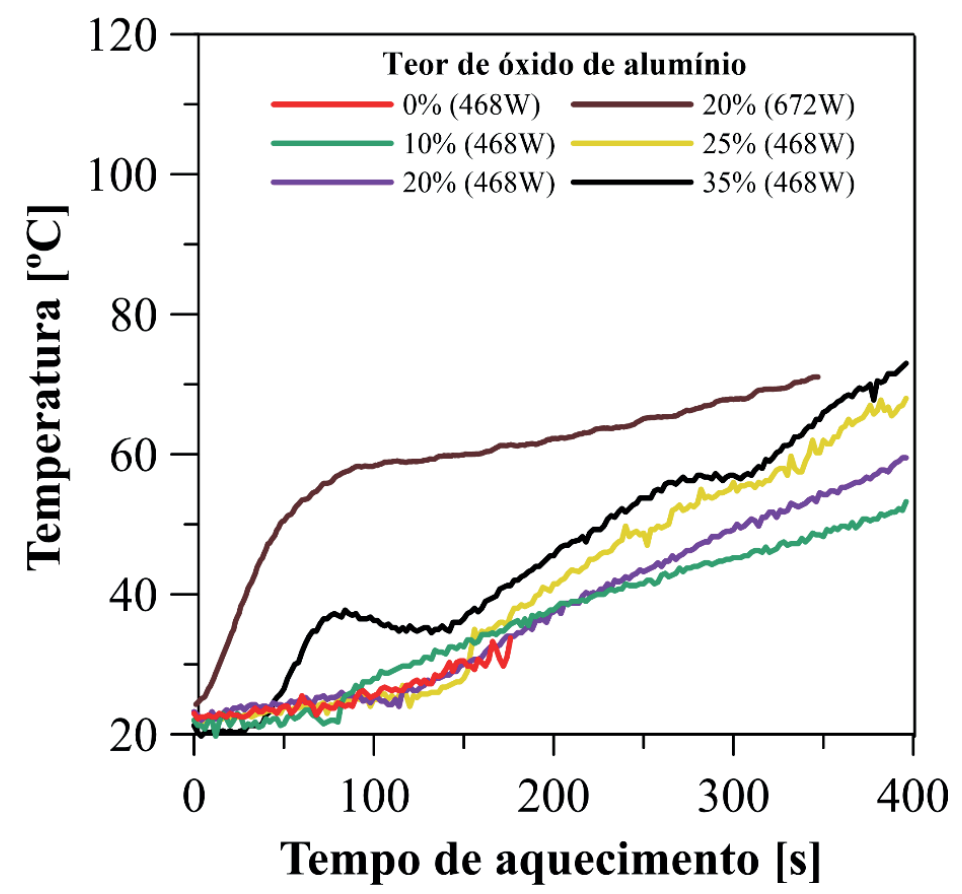

Fonte: Autoria própria

Aumentando a potência de $468 \mathrm{~W}$ para $672 \mathrm{~W}$, é possível constatar uma instabilidade no aquecimento do arenito, principalmente no primeiro minuto de aquecimento, no qual é verificado uma subida brusca da temperatura. Após essa instabilidade, o aquecimento do arenito segue a mesma tendência dos testes a $468 \mathrm{~W}$, porém com temperaturas mais altas.

A cinética de aquecimento da areia misturada com óxido de manganês com teor de 10, 20, 25 e $35 \%$ aquecido a uma potência de $468 \mathrm{~W}$ é apresentada na Figura 4 . 
Figura 4 - Cinética de aquecimento areia com diferentes teores de óxido de manganês e potências.

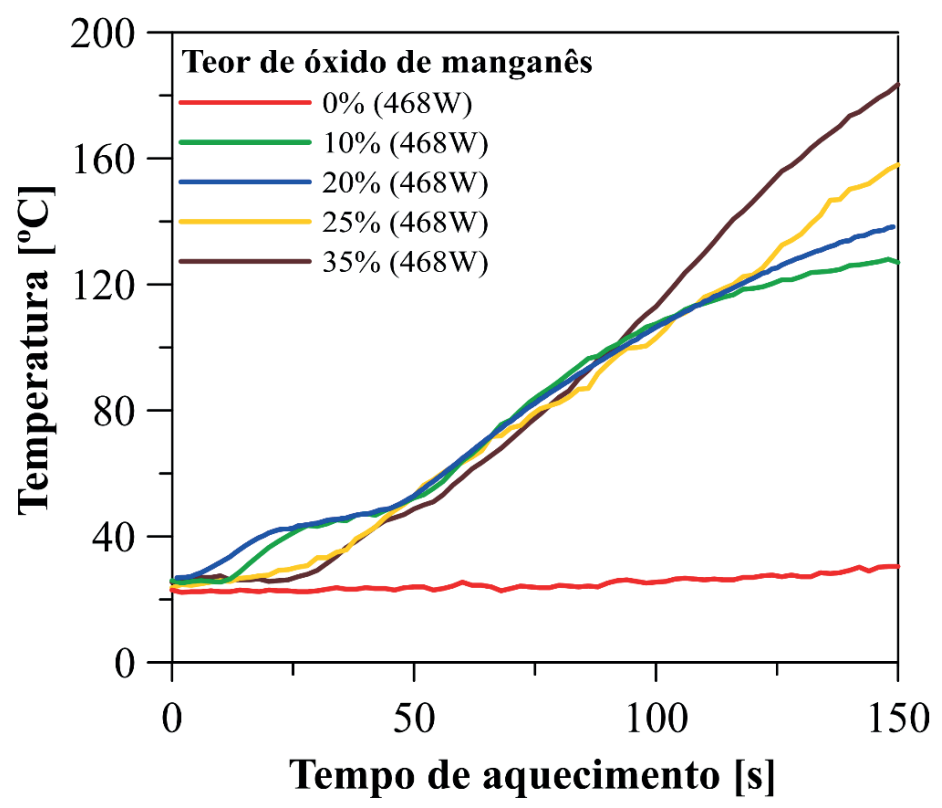

Fonte: Autoria própria

A Figura 4 mostra que a presença do óxido de manganês surtiu grande efeito na curva de cinética de aquecimento com relação ao teste branco $(0 \%)$. A diferença de inclinação entre as curvas só pôde ser visualizada após o material atingir temperaturas acima de $110^{\circ} \mathrm{C}$. A partir dessa temperatura, é possível constatar que, com o aumento do teor de óxido de manganês, há um aumento na temperatura do arenito, atingindo temperaturas bastante elevadas, classificando o óxido de manganês como bom absorvedor de micro-ondas, atingindo temperaturas altas mesmo após 2,5 minutos de aquecimento.

Experimentalmente, foi constatado que, após 2,5 minutos de aquecimento, havia um comportamento anormal da temperatura do arenito, não sendo possível constatar se o comportamento estava ligado ao óxido de manganês ou à falha do magnetron.

A Figura 5 mostra a cinética de aquecimento do arenito misturada com óxido de cálcio a 10 e $20 \%$ aquecidos a $672 \mathrm{~W}$. 
Figura 5 - Cinética de aquecimento areia com diferentes teores de óxido de cálcio.

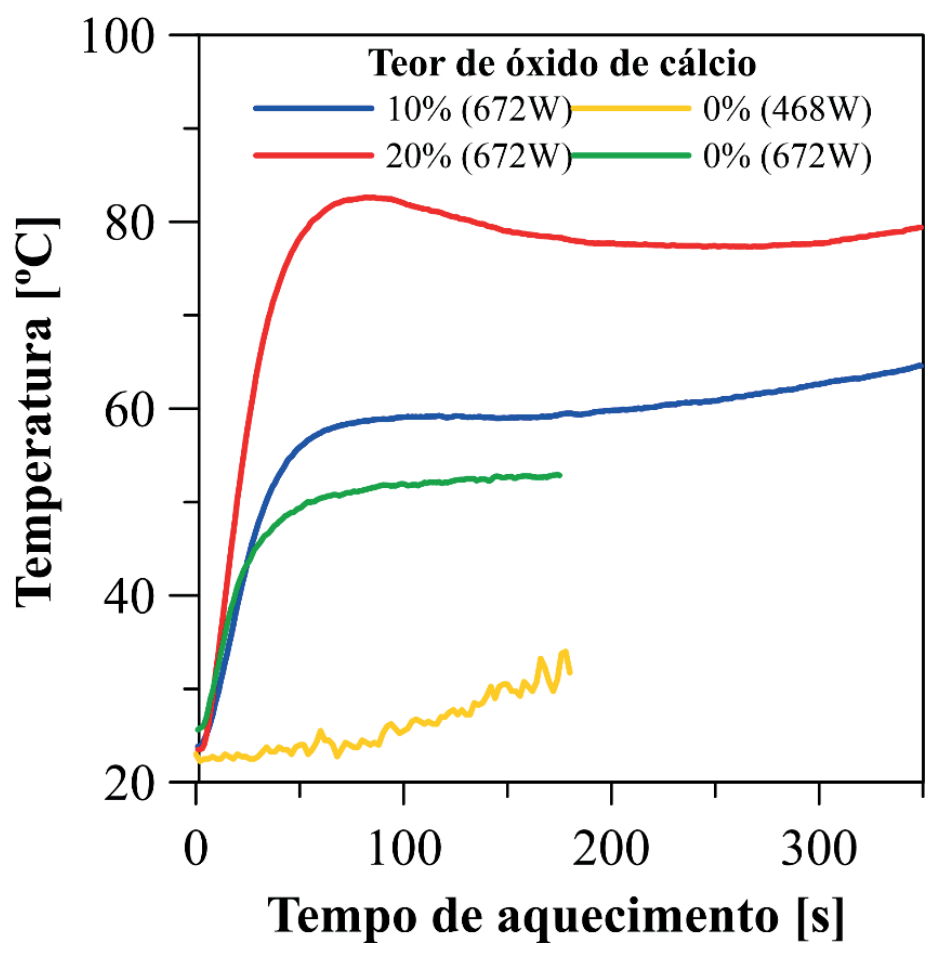

Fonte: Autoria própria

Os resultados da Figura 5 corrobora que, utilizando-se uma maior potência, é possível alcançar maiores temperaturas no arenito puro. Além disso, a utilização do óxido de cálcio promove um pequeno aumento na temperatura do arenito, porém não tão significativo quanto ao obtido com os óxidos anteriores. 0 aumento do teor de óxido de cálcio melhora a inclinação das curvas de cinética de aquecimento e pronuncia a instabilidade inicial. Essa instabilidade foi observada também com a utilização do óxido de alumínio.

Devido às baixas temperaturas alcançadas, mesmo após 6 minutos de aquecimento, o óxido de cálcio pode ser considerado um óxido com insatisfatória absorção de micro-ondas.

Para verificar a influência da potência aplicada e dos teores de óxidos nas taxas de aquecimento, foram convertidas as curvas de cinética de aquecimento em curvas de taxa de aquecimento, e os valores médio dessas taxas são apresentadas na Tabela 2.

A análise da Tabela 2 mostra que há uma proporcionalidade entre os teores dos óxidos e a taxa de aquecimento. À medida que o teor aumenta, a taxa de aquecimento também mantém o mesmo comportamento. Com relação à aplicação de uma maior potência, a taxa de aquecimento também aumenta, devido a uma maior incidência das micro-ondas.

O óxido de ferro apresentou maiores taxas de aquecimento devido ao fato de o ferro apresentar propriedades eletromagnéticas favoráveis à incidência das micro-ondas, assim como o óxido de manganês. Já o óxido de alumínio e o óxido de cálcio, apresentaram taxas de aquecimento bastante baixas. 
Tabela 2 - Taxa de aquecimento do arenito misturado com óxidos.

\begin{tabular}{|c|c|c|c|}
\hline Óxido & $\begin{array}{l}\text { Teor } \\
{[\%]}\end{array}$ & $\begin{array}{l}\text { Potência } \\
\text { [W] }\end{array}$ & $\begin{array}{c}\text { Taxa de aquecimento } \\
{\left[{ }^{0} \mathrm{C} / \mathrm{min}\right]}\end{array}$ \\
\hline \multirow{7}{*}{$\mathrm{Fe}$} & 0 & 468 & 3,92 \\
\hline & 0 & 672 & 5,70 \\
\hline & 10 & 468 & 12,58 \\
\hline & 20 & 468 & 20,29 \\
\hline & 25 & 468 & 27,46 \\
\hline & 25 & 672 & 39,20 \\
\hline & 35 & 468 & 56,21 \\
\hline \multirow{6}{*}{ Al } & 0 & 468 & 3,92 \\
\hline & 10 & 468 & 5,17 \\
\hline & 20 & 468 & 6,17 \\
\hline & 20 & 672 & 7,45 \\
\hline & 30 & 468 & 9,39 \\
\hline & 35 & 468 & 8,67 \\
\hline \multirow{5}{*}{$\mathrm{Mn}$} & 0 & 468 & 3,92 \\
\hline & 10 & 468 & 33,67 \\
\hline & 20 & 468 & 38,67 \\
\hline & 25 & 468 & 51,08 \\
\hline & 35 & 468 & 64,25 \\
\hline \multirow{4}{*}{$\mathrm{Ca}$} & 0 & 468 & 3,92 \\
\hline & 0 & 672 & 5,70 \\
\hline & 10 & 672 & 7,01 \\
\hline & 20 & 672 & 9,61 \\
\hline
\end{tabular}

Fonte: Autoria própria

Analisando-se a tendência dos resultados, nesta pesquisa, foi proposta uma equação para relacionar a Taxa de Aquecimento $\left(\mathrm{TA} \mathrm{em}{ }^{\circ} \mathrm{C} / \mathrm{min}\right.$ ) dos arenitos com o Teor de Óxidos (x em g de óxido/g de arenito), a Taxa de Aquecimento do Arenito Puro $\left(\mathrm{TA}_{0} \mathrm{em}{ }^{\circ} \mathrm{C} / \mathrm{min}\right)$, Constante que depende do tipo de óxido (c) e Potência aplicada ( $P$ ), assim como mostrado pela Equação 1.

$$
\mathrm{TA}=\mathrm{TA}_{0}+\mathrm{C} * \mathrm{P} * \mathrm{X}
$$

Ajustando-se os resultados da Tabela 2 na Equação 1, é possível encontrar os valores da Constante do óxido (c) com os respectivos $\mathrm{R}^{2}$, assim como mostrado pela Tabela 3.

Tabela 3 - Valores da constante de óxido ajustados nesta pesquisa.

\begin{tabular}{ccc}
\hline Óxido & $\begin{array}{c}\mathbf{c} \\
{\left[{ }^{\circ} \mathbf{C}(\mathbf{m i n} * \mathbf{W})\right]}\end{array}$ & $\mathbf{R}^{2}$ \\
\hline $\mathbf{F e}$ & 236,97 & 0,9087 \\
\hline $\mathbf{A l}$ & 31,57 & 0,9158 \\
\hline $\mathrm{Mn}$ & 389,44 & 0,9264 \\
\hline $\mathrm{Ca}$ & 27,17 & 0,9807 \\
\hline
\end{tabular}

Fonte: Autoria própria 
Os resultados de $\mathrm{R}^{2}$ apresentados na Tabela 3 mostram a boa concordância da correlação proposta com os resultados experimentais de taxa de aquecimento. Os valores da constante do óxido apresentaram valores muito altos para óxidos, com boa absorção de micro-ondas, e valores muito baixos para óxidos, com baixa absorção de micro-ondas. Dessa forma, é possível mensurar o grau de interação dos óxidos com as micro-ondas em valores quantitativos, não sendo necessário mais aplicar os conceitos qualitativos de bom/insatisfatório absorvedor, assim como visto largamente na literatura (CHEN et al., 1984; PETRI JÚNIOR et al., 2017). Quanto maior a constante c, maior será a taxa de aquecimento do arenito. Essa constante também está ligada ao tipo de óxido presente no material.

Por ser uma correlação geral, que inclui os principais parâmetros existentes durante um aquecimento de materiais rochosos, pode ser aplicada não somente às condições estudadas nesta pesquisa, mas também ser ampliada para outros tipos de equipamentos. Em próximos trabalhos, serão avaliados os valores da constante "c" para o caso de mistura de óxidos em arenitos.

\section{CONCLUSÕES}

Com base nos dados obtidos, foi possível concluir que o óxido de ferro III e óxido de manganês tem maior interação com as micro-ondas, em relação aos demais óxidos, pois a temperatura máxima e a taxa de aquecimento de ambos foram consideravelmente superiores. Devido às melhores propriedades dielétricas presentes nesses óxidos, eles são mais sensíveis às ondas eletromagnéticas, apresentando-se melhores absorvedores de micro-ondas. Foi observado um comportamento anormal durante 0 aquecimento desses óxidos, mostrando que podem ser instáveis em teores mais elevados, levando a um superaquecimento do arenito.

O óxido de alumínio e de cálcio apresentaram baixas taxas de aquecimento comparado aos outros óxidos estudados, devido às propriedades eletromagnéticas desses óxidos não serem favoráveis a interação com as micro-ondas, fato comprovado através das constantes de óxido calculadas.

Nos testes de aumento da potência aplicada, as taxas de aquecimento dos óxidos estudados aumentaram, sendo isso desfavorável para que se realize uma descontaminação do cascalho de forma mais eficiente, pois taxas de aquecimento menores favorecem a uma melhor descontaminação.

Com os resultados obtidos pela correlação, pôde-se conhecer melhor a influência dos teores de diferentes óxidos na taxa de aquecimento. Por ser uma correlação geral, pode ser aplicada em condições operacionais de secadores micro-ondas em escala industrial e operação contínua.

\section{AGRADECIMENTOS}

Os autores agradecem o apoio técnico-financeiro proporcionado pela FAPEMIG (APQ-00022-18), CNPq (427962/2018-8), PETROBRAS (Termo de Cooperação nº 5850.0107572.18.9 PETROBRAS/UFU/ FAU) e UFLA (PIDEG76-2018). 


\section{REFERÊNCIAS}

CHEN, T. T.; DUTRIZAC, J. E.; HAQUE, K. E.; WYSLOUZIL, W.; KASHYAP, S. The Relative Transparency of Minerals to Microwave Radiation. Canadian Metallurgical Quarterly, [S.L.], v. 23, n. 3, p. 349-351, jul. 1984. Informa UK Limited. Disponível em: http://dx.doi.org/10.1179/cmq.1984.23.3.349. Acesso em: 31. jan. 2021.

INSTITUTO NACIONAL DE METROLOGIA, QUALIDADE E TECNOLOGIA (Brasil). Portaria $\mathbf{n}^{\circ} \mathbf{1 7 4 / 2 0 1 2}$ Regulamento técnico da qualidade para fornos de microondas. Rio de Janeiro: INMETRO, 2012. 22 p.

INTERNATIONAL ELECTROTECHNICAL COMMISSION (International Standard). IEC 60705: Household microwave ovens - Methods for measuring performance. Genebra: International Electrotechnical Commission, 2018. 208 p.

JAVAD, S. M.; BARANI, Kianoush. Microwave Heating Applications in Mineral Processing. The Development and Application of Microwave Heating, [S.L.], p. 79-104, 7 nov. 2012. InTech. Disponível em: http://dx.doi. org/10.5772/45750. Acesso em: 31. jan. 2021.

PANISSET, C. M. A. Novas alternativas para o sistema de separação sólido-líquido na perfuração de poços de petróleo: teste de uma unidade de VCS; busca do aumento de eficiência da operação de hidrociclonagem; e tratamento da borra de centrifugação por micro-ondas. 2014. $1 \mathrm{v}$. Tese (Doutorado) - Curso de Engenharia Química, Universidade Federal de Uberlândia, Uberlândia, 2014.

PEREIRA, M. S., Aplicação de secagem por micro-ondas no tratamento do cascalho de perfuração. 2013. 122 f. Tese (Doutorado) - Curso de Engenharia Química, Universidade Federal de Uberlândia, Uberlândia, 2013.

PETRI JÚNIOR, Irineu; MARTINS, André Leibsohn; ATAÍDE, Carlos H.; DUARTE, Cláudio R. Microwave drying remediation of petroleum-contaminated drill cuttings. Journal Of Environmental Management, [S.L.], v. 196, p. 659-665, jul. 2017. Elsevier BV. Disponível em: http://dx.doi.org/10.1016/j.jenvman.2017.03.068. Acesso em: 31. jan. 2021.

ROBINSON, J. P.; KINGMAN, S.W.; SNAPE, C. E.; BARRANCO, R.; SHANG, H.; BRADLEY, M. S. A.; BRADSHAW, S. M. Remediation of oil-contaminated drill cuttings using continuous microwave heating. Chemical Engineering Journal, [S.L.], v. 152, n. 2-3, p. 458-463, 15 out. 2009. Elsevier BV. Disponível em: http:// dx.doi.org/10.1016/j.cej.2009.05.008. Acesso em: 31. jan. 2021.

SHANG, Hui; SNAPE, Colin E.; KINGMAN, Sam W.; ROBINSON, John P. Treatment of Oil-Contaminated Drill Cuttings by Microwave Heating in a High-Power Single-Mode Cavity. Industrial \& Engineering Chemistry Research, [S.L.], v. 44, n. 17, p. 6837-6844, ago. 2005. American Chemical Society (ACS). Disponível em: http://dx.doi.org/10.1021/ie0500772. Acesso em: 31. jan. 2021. 